\title{
Plasma testosterone in preterm infants with cryptorchidism
}

\author{
B A BAKER, ${ }^{*}$ R MORLEY, ${ }^{*}$ AND A LUCAS ${ }^{*} \dagger$ \\ ${ }^{*}$ MRC Dunn Nutrition Unit and +University Department of Paediatrics, Cambridge
}

SUMMARY Cryptorchidism is common in infants born preterm, yet the mechanism for its occurrence is still debated. In a study of 21 premature babies with cryptorchidism at 18 months post-term and 21 case matched controls, cryptorchid preterm infants failed to show the normal rise in plasma testosterone in the first postnatal week. This rise is thought to relate to residual maternal human chorionic gonadotrophin in the neonatal circulation. Infants with cryptorchidism also failed to show the later testosterone surge in the second month which has been related to endogenous gonadotrophin release. We speculate that inadequate stimulation of testosterone release by human chorionic gonadotrophin in the fetus might contribute to the pathogenesis of cryptorchidism in preterm infants. Our findings have implications for the medical treatment or possible prophylaxis of undescended testes in premature babies.

Cryptorchidism has received considerable scientific attention, yet its aetiology is still debated. Substantial evidence supports the view that there is an underlying disturbance of testosterone and gonadotrophin secretion in this condition. ${ }^{1-4}$ In normal term and preterm infants, high concentrations of plasma testosterone, close to adult values, are found during the first postnatal week, in association with residual human chorionic gonadotrophin in the neonatal circulation. ${ }^{5}{ }^{6}$ Subsequently, plasma testosterone concentrations fall, only to rise again in the second month under the influence of an endogenous surge in luteinising hormone. ${ }^{5-7}$ In cryptorchidism this later surge in both luteinising hormone and testosterone is diminished. ${ }^{2}{ }^{2}$ Moreover, there is evidence that from infancy to puberty, children with undescended testes have reduced luteinising hormone responsiveness to luteinising hormone releasing hormone and reduced testosterone responsiveness to human chorionic gonadotrophin. ${ }^{89}$

Previous endocrinological studies on cryptorchidism have focused primarily on infants born at full term. We have reported a very high incidence of cryptorchidism in premature babies at 18 months' corrected age, reaching $19 \%$ in infants of less than $1000 \mathrm{~g}$ birth weight. ${ }^{10}$ The aetiology of cryptorchidism in this special, high risk group has received little attention. In this study we have investigated plasma testosterone concentrations during the first three months postpartum in 21 preterm infants with cryptorchidism and in 21 case matched controls.

\section{Subjects and methods}

The study population included 21 babies born preterm, at a mean (SE) gestation of $30(0 \cdot 4)$ weeks, who were found to have cryptorchidism at 18 months' corrected age. Clinical details of these infants have been described. ${ }^{10}$ Ten subjects had bilateral and 11 subjects unilateral cryptorchidism. Venous blood samples from these infants were available until they were discharged from hospital, at a median age of 40 days (range 17-90). Samples were taken at mean postnatal ages of 2 and 5 days, and then weekly until discharge.

A further group of 21 control infants were studied, each of whom had been matched carefully with an index case for (in order of priority) gestation, birth weight, duration of ventilatory assistance and, in view of the evidence that phototherapy may induce gonadotrophin release, ${ }^{11}$ the cases were matched also for duration of phototherapy.

Venous plasma samples were collected, without haemolysis, into cooled heparinised tubes, centrifuged at $4^{\circ} \mathrm{C}$, frozen within 30 minutes of sampling, and stored at $-20^{\circ} \mathrm{C}$. Plasma testosterone concentration was measured in duplicate $60 \mu \mathrm{l}$ samples, by radioimmunoassay after extraction into diethyl ether, using the method described by Wheeler and Luther. ${ }^{12}$ The sensitivity of the assay was $0 \cdot 1 \mathrm{nmol} / \mathrm{l}$. The antiserum cross reacted with dihydrotestosterone $(20 \%)$, but had negligible cross reactions with 
androstenediol, androstenedione, oestradiol, progesterone, and cortisol.

Statistical analyses were performed using Student's $t$ test and, when data sets were highly skewed, the Mann-Whitney rank sum test.

\section{Results}

Mean gestation, birth weight, days of mechanical ventilation required, and days of phototherapy were compared in index cases and controls, who were closely matched for these factors; the results are shown in the table.

The figure shows plasma testosterone concentrations in index cases and controls at mean ages of 2 and 5 days, weekly from week two to six and beyond week six (mean age 67 days; maximum 85 days). As samples were not always available at all periods for each subject unpaired $t$ tests (or rank sum tests) were used for statistical comparisons. The decrease in sample numbers beyond week five resulted from

Table Mean (SE) birth weight, gestation, days of mechanical ventilation, and days of phototherapy in 21 preterm infants with cryptorchidism diagnosed at 18 months' corrected age, and in 21 case matched case controls without cryptorchidism

\begin{tabular}{lcr}
\hline & $\begin{array}{l}\text { Index cases } \\
(n=21)\end{array}$ & $\begin{array}{l}\text { Controls } \\
(n=21)\end{array}$ \\
\hline Birth weight (g) & $1318(56)$ & $1339(56)$ \\
Gestation (weeks) & $30(0 \cdot 4)$ & $30(0 \cdot 3)$ \\
Ventilation (days) & $4(1)$ & $4 \begin{array}{l}(1) \\
\text { Phototherapy (days) }\end{array}$ \\
\hline
\end{tabular}

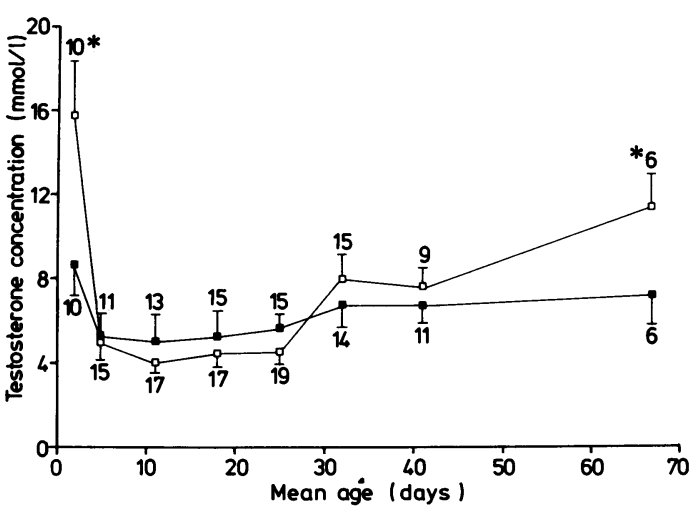

Figure Plasma testosterone concentrations in preterm infants with cryptorchidism diagnosed at 18 months' post-term (closed squares) and in case matched infants without cryptorchidism (open squares) at eight periods during the first three months postpartum. Asterisk indicates significant differences between index cases and controls. discharge of some subjects from hospital. In the last period, six subjects in each group remained in the study and the testosterone value for each subject was the mean for samples taken beyond week six.

At 2 days, index cases had significantly lower mean (SE) concentrations of plasma testosterone than controls: $8.6(1.5)$ compared with $15.7(2.6)$ $\mathrm{nmol} / \mathrm{l}, \mathrm{p}<0 \cdot 01$. In the controls a nadir in plasma testosterone concentration had been achieved by 11 days with a highly significant fall in testosterone values to $4 \cdot 0(0 \cdot 4) \mathrm{nmol} / \mathrm{l}, \mathrm{p}<0 \cdot 001$. In contrast, the fall in plasma testosterone in the index cases over this period to $5.0(1.2) \mathrm{nmol} / \mathrm{l}$ did not reach significance. In the controls, plasma testosterone concentrations rose from the 11 day value to 8.0 $(1.1) \mathrm{nmol} / 1$ in week five $(\mathrm{p}<0.001)$ and to $11.4(1.5)$ $\mathrm{nmol} / \mathrm{l}$ beyond week six $(\mathrm{p}<0 \cdot 001)$. The index cases, however, showed no significant rise in plasma testosterone concentration during this period. Beyond six weeks, the difference in values between index cases and controls-11.4 (1.5) compared with $7 \cdot 1(1 \cdot 3)$-reached significance $(\mathrm{p}<0 \cdot 05)$.

No relationship was found between plasma testosterone concentrations and the duration of phototherapy in any of the postnatal groups studied.

\section{Discussion}

We have shown that preterm infants in whom cryptorchidism was diagnosed at 18 months postterm failed to develop the normal testosterone surge in the second postnatal month. Thus preterm infants with undescended testes appear to be similar in this respect to full term infants with this condition. ${ }^{12}$ There have been no previous reports, however, in either term or preterm infants with cryptorchidism, on plasma testosterone concentrations in the period immediately postpartum. We observed that preterm infants with this condition showed no primary rise of plasma testosterone, normally seen in both term and preterm infants early in the first week after birth, ${ }^{5}$ and indeed seen in the case matched controls in this study.

We have observed that, below 32 weeks' gestation, there is an abrupt rise in the incidence of undescended testes. ${ }^{10}$ These data raised the question of whether the aetiology of cryptorchidism in preterm infants differed from that in infants born at term. Our data suggest, however, that a diminution of testosterone release is a consistent feature in cryptorchidism, even if it occurs in the preterm infant. It might be supposed that such reduced testosterone secretion reflected a more general immaturity of the Leydig cells or the hypothalamuspituitary-gonadal axis in babies born preterm. Yet our matched controls showed an early rise in plasma 
testosterone concentration, and Forest and others have shown that the surge in testosterone seen in the second month is normally higher in preterm than in term, male infants without undescended testes. ${ }^{5} \mathrm{We}$ have considered the possibility that cryptorchidism, at least in premature babies, may not be due to a primary endocrine defect in the infant, but to a lack of a stimulatory influence that should have occurred in utero. Our data obtained on the second day postpartum are relevant in this respect; the relatively low concentrations of plasma testosterone immediately after birth in babies with cryptorchidism could imply that inadequate release of testosterone induced by maternal chorionic gonadotrophin in utero was the initial endocrine lesion. Further study is required on perinatal endocrine interrelations in premature babies to explore this hypothesis.

A number of investigators have advocated medical treatment for cryptorchidism, though the efficacy of this approach is debated. ${ }^{13} 14$ Gonadotrophin and testosterone have been implicated in testicular descent and, on this basis, treatment with luteinising hormone releasing hormone has been used with varying success. ${ }^{13-16}$ Systemic testosterone alone results in testicular descent in primates, ${ }^{17}$ and human chorionic gonadotrophin has been used successfully in cryptorchidism in man. ${ }^{18}$ We suggest that the high incidence of undescended testes in preterm babies, and our findings that their primary and secondary rise in testosterone are diminished, would make it logical to explore endocrine treatment or prophylaxis in this special group.

We wish to thank Drs Bamford, Dossetor, Boon, Pearse, and Crowle for their help in the neonatal units at Ipswich, King's Lynn, Sheffield, and Norwich; Dr Malcolm Pike and Dr Clare Chilvers for their initial encouragement to undertake the project, and Farley Health Products Limited for financial help.

\footnotetext{
References

1 Gendrel D, Roger M, Job J-C. Plasma gonadotropin and testosterone values in infants with cryptorchidism. J Pediatr 1980;97:217-20.

${ }^{2}$ Gendrel D, Job J-C, Roger M. Reduced post-natal rise of
}

testosterone in plasma of cryptorchid infants. Acta Endocrinol $\bigcirc$ (Copenh) 1978;89:372-8.

${ }^{3}$ Hadziselimovic F, Thommen L, Girard J, Herzog B. The significance of postnatal gonadotropin surge for testicular $\overrightarrow{\vec{B}}$ development in normal and cryptorchid testes. J Urol 1986;136: 274-6.

${ }^{4}$ Waaler PE. Endocrinological studies in undescended testes. Acta Paediatr Scand 1976;65:559-64.

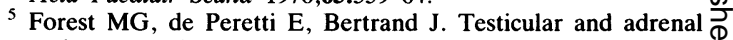
androgens and their binding to plasma proteins in the perinatal $\varrho$ period: developmental patterns of plasma testosterone, 4- ڤ androstenedione, dehydroepiandrosterone and its sulfate in premature and small for date infants as compared with that of $\vec{O}$ full-term infants. J Steroid Biochem 1980;12:25-36.

${ }^{6}$ Winter JSD, Faiman C, Hobson WC, Prasad AV, Reyes FI. $\vec{\omega}$ Pituitary-gonadal relations in infancy-1. Patterns of serum gonadotropin concentrations from birth to four years of age in man and chimpanzee. J Clin Endocrinol Metab 1975;40:545-51. ?

${ }^{7}$ Ryle M, Stephenson J, Williams J, Stuart J. Serum gonadotrophins in young children. Clin Endocrinol (Oxf) 1975;4:413-9.

8 Job JC, Garnier PE, Chaussain JL, Toublanc JE, Canlorbe P. $\vec{\circ}$ Effect of synthetic LHRH in hypophysogonadal disorders of children and adolescents. IV. Undescended testes. J Pediatr $\vec{\oplus}$

${ }^{9}$ Gendrel D, Job JC, Canlorbe P, Roger M, Laclyde JP. Donnees 음 endocriniennes dans les cryptorchidies. Arch Fr Pediatr 1978;35: 535.

${ }^{10}$ Morley R, Lucas A. Undescended testes in preterm infants. $\mathrm{Br}$ Med J 1987;295:753.

11 Lemaitre B, Toubas L, Guillot M, Dreux C, Relier JP. Changes of serum gonadotropin concentrations in premature babies submitted to phototherapy. Biol Neonate 1977;32:113-8.

12 Wheeler MJ, Luther F. Development of testosterone assays routine use. In: Hunter WM, Corrie JET, eds. Immunoasso $œ$ for clinical chemistry. Edinburgh: Churchill Livingstone, 1983웡 113-6.

13 Anonymous. The undescended testis: is there a role for LHRH? [Editorial]. Lancet 1986;i:1133-4.

14 Chilvers C, Jackson MB, Pike MC. Luteinising-hormonereleasing hormone and cryptorchidism. Lancet 1986;(ii):101. त

15 Raifar J, Handelsman DJ, Swerdloff RD, et al. Hormonal therapy of cryptorchidism. $N$ Engl J Med 1986;314:466-70. ते

16 de Muinck Keizer-Schrama SMPF, Hazebroek FWJ, Matroos 3 AW, Drop SLS, Molenaar JC, Visser HKA. Double-blind placebo-controlled study of luteinsing-hormone-releasing hormone nasal spray in treatment of undescended testes. Lancet 1986;: :876-80.

17 Hamilton JB. The effect of male hormone upon the descent of 응 the testes. Anat Rec 1938;70:533-41.

${ }^{18}$ Schapiro B. Ist der kryptorchismus chirurgische oder hormonal zu behandeln. Dsch Med Wochenschr 1931;57:718.

Correspondence to Dr A Lucas, MRC Dunn Nutrition Unit, Downhams Lane, Milton Road, Cambridge CB4 1XJ.

Accepted 27 November 1987 